\author{
Paul A. Gleeson
}

\title{
Targeting of proteins to the Golgi apparatus
}

\author{
Accepted: 15 October 1997
}

\begin{abstract}
The proteins that reside in the Golgi carry out functions associated with post-translational modifications, including glycosylation and proteolytic processing, membrane transport, recycling of endoplasmic reticulum proteins and maintenance of the structural organisation of the organelle itself. The latter includes Golgi stacking, interconnections between stacks and the microtubule-dependent positioning of the organelle within the cell. There are a number of distinct groups of Golgi membrane proteins, including glycosyltransferases, recycling trans-Golgi network (TGN) proteins, peripheral membrane proteins and receptors. Considerable effort has been directed at understanding the basis of the localisation of Golgi glycosyltransferases and recycling TGN proteins; in both cases there is increasing evidence that multiple signals may be involved in their specific localisation. A number of models for the Golgi retention of glycosyltransferases have been proposed including oligomerisation, lipid-mediated sorting and intra-Golgi retrograde transport. More information is required to determine the contribution of each of these potential mechanisms in the targeting of different glycosyltransferases. Future work is also likely to focus on the relationship between the localisation of resident Golgi proteins and the maintenance of Golgi structure.
\end{abstract}

\section{Introduction}

Camillo Golgi (1844-1926) not only discovered the Golgi apparatus (Golgi 1898) but also, in an unrelated set of experiments, provided the first description of a secretory process, namely acid secretion by gastric parietal cells (Golgi 1893). Little did he know at the time, however, that his "internal reticular apparatus" was also intimately

\section{P.A. Gleeson}

Department of Pathology and Immunology,

Monash University Medical School, Commercial Road,

Prahran, Victoria 3181, Australia

Tel. +61 39276 2714; fax +61 395296484

e-mail pag@cobra.path.monash.edu.au involved in a secretory pathway which was ubiquitous in eucaryotic cells.

The electron microscopic studies of the 1950s provided convincing evidence for the existence of a Golgi organelle and the first detailed structural description of this complex organelle (see review by Farquhar and Palade 1981). These early morphological studies initiated the challenge to biochemists and cell biologists to unravel the function of this organelle. In the 1960s the application of autoradiography demonstrated that secretory proteins moved through the Golgi apparatus and that this organelle was involved with glycoprotein biosynthesis. In particular, the classic studies of Leblond and co-workers (Neutra and Leblond 1996a, b) using electron microscopy combined with autoradiography demonstrated that the Golgi stack was the cellular site for the incorporation of various monosaccharides into glycoproteins (Fig. 1). The subsequent development of methods to isolate highly enriched Golgi membrane fractions led to the discovery that the glycosyltransferase responsible for the synthesis of $N$-acetyllactosamine, namely $\beta 1,4$-galactosyltransferase $(\beta 1,4 \mathrm{GalT})$, was highly enriched in Golgi membranes (Fleischer et al. 1969; Morré et al. 1969; Schachter et al. 1970). The presence of this membrane-bound enzyme specifically associated with Golgi fractions was a pivotal finding as it definitely showed that the Golgi apparatus had the enzymic machinery necesssary for glycosylation and, in addition, provided a marker enzyme to monitor cell fractionation, which remains the marker of choice today. Moreover, these collective findings gave a cell biological focus to the biochemistry of glycosylation. We now know that the Golgi apparatus plays a major role in the biosynthesis of glycolipids, the glycan chains of glycoproteins and proteoglycans and polysaccharides of plant cells.

The purification of glycosyltransferases allowed the production of specific antibodies for immunocytochemistry. Immunocytochemical localisation of $\beta 1,4 \mathrm{GalT}$ to the trans-Golgi (Roth and Berger 1982) and $\alpha 2,6$-sialyltransferase $(\alpha 2,6 \mathrm{ST})$ to predominantly the trans-Golgi network (TGN) (Roth et al. 1985) confirmed the view that 


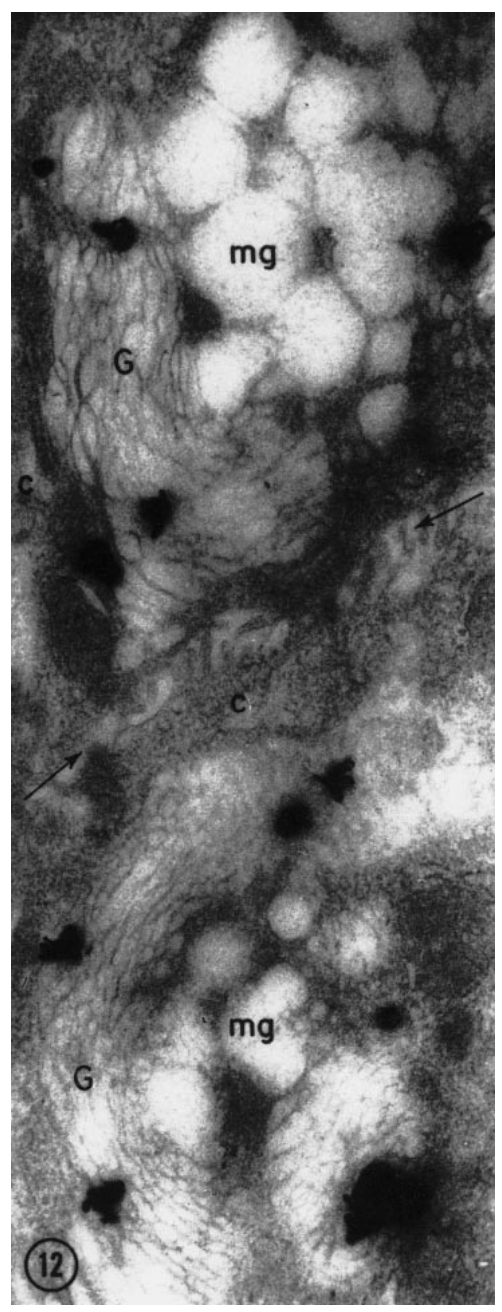

Fig. 1 Electron microscope autoradiography demonstrating synthesis of glyco-conjugates in the Golgi apparatus. Electron micrograph is taken from Neutra and Leblond (1966b) with permission. Autoradiograph of rat colon goblet cells at $5 \mathrm{~min}$ after local injection of $\left[{ }^{3} \mathrm{H}\right]$-glucose, showing a transverse section through the supranuclear region of two goblet cells (arrows indicate intercellular space). Silver grains overlie the stacks of Golgi saccules $(G)$. Neither the central mucigen granules $(m g)$ nor the peripheral cytoplasm $(c)$ are labelled. $\times 21000$

the Golgi consists of multiple compartments and further demonstrated a relationship between the ordered sequence of reactions of the glycosylation pathway and the relative location of the enzymes within the Golgi stacks. Subcellular fractionation of Golgi membranes also provided supporting evidence for the compartmentalisation of Golgi enzymes (Dunphy and Rothman 1983; Goldberg and Kornfeld 1983). The highly specific localisation of these membrane-bound enzymes raised fascinating questions about how these proteins were targeted and retained within specific regions of the Golgi apparatus. However, the ability to approach this intriguing question experimentally only became a reality after Golgi glycosyltransferases began to be cloned in the mid to late 1980s.

At the same time that the first endogenous Golgi proteins were being cloned, an alternative approach to dis- sect the molecular basis for the localisation of resident Golgi proteins was developed through the study of enveloped viruses. Enveloped viruses have proved very useful in understanding the pathways of intracellular transport in eucaroytic cells. A number of intracellular viruses acquire their envelopes by budding into the lumen of the Golgi apparatus, after which the mature virus is transported from the cell (Pettersson 1991; Griffiths and Rottier 1992). Enveloped viruses from Golgi membranes have been shown to encode one or more membrane proteins which are specifically targeted to distinct regions within the Golgi apparatus. Indeed, the first Golgi localisation signal was identified in the E1 or M glycoprotein of the coronavirus, avian infectious bronchitis virus (IBV). Avian coronavirus $\mathrm{M}$ protein has three membrane-spanning domains and deletion analysis suggested that a Golgi localisation signal may be contained within the first membrane-spanning domain of IBV M protein (Machamer and Rose 1987). The surprising finding that a hydrophobic sequence may contain a Golgi retention signal lay the foundations for the subsequent analyses of glycosyltransferases a few years later.

The Golgi apparatus is not only a carbohydrate factory but also represents the hub of the secretory pathway where intense membrane traffic is controlled. Vesicles are thought to bud from one compartment and then target and fuse with the next compartment (Rothman and Orci 1992; Rothman 1994). An increasing number of structural and regulatory components have been identified which are involved in the orchestration of the complex and intriguing processes of budding, specific targeting, docking and fusion (Pryer et al. 1992; Rothman 1994; Schekman and Orci 1996.) Some of the components of this machinery are localised specifically to Golgi membranes and are thought to be specific for membrane transport through and from the Golgi apparatus. The restricted location of these components implies the presence of specific localisation signals.

A fundamental question currently being addressed in cell biology is how the Golgi apparatus is organised to achieve the demanding functions of glycosylation and membrane transport and how its structural integrity is maintained in spite of the intense membrane traffic which enters and leaves this organelle. This review will focus on our understanding of the molecular signals and mechanisms for the retention of resident Golgi proteins which carry out these diverse functions.

\section{Compartmentalisation of the Golgi}

Understanding how resident Golgi proteins are localised requires an appreciation of the structure of this organelle and the mechanism by which newly synthesised proteins move through the Golgi apparatus. The classic image of the Golgi is that of a set of flattened cisternae with dilated rims. The organelle is organised into functionally distinct regions; the Golgi stack (consisting of cis, medial and trans cisternae) and two flanking tubular networks of 
membrane (Mellman and Simons 1992). The cis-Golgi network (CGN), probably equivalent to the (ER)-Golgi intermediate compartment or salvage compartment, is considered to be the compartment which receives newly synthesised proteins from the ER. It is also involved in the recycling of lipids and ER-associated proteins, which have leaked out of the ER, by backward or retrograde transport. The highly dynamic nature of the CGN has resulted in considerable controversy as to to the exact relationship of this compartment with the ER and Golgi stack (Hauri and Schweizer 1992; Krijnse Locker et al. 1994a). In view of this uncertainty, the CGN/intermediate compartment will be not be included in this review. The TGN is situated at the distal face of the Golgi stack, is functionally distinct from the trans-cisternae, and is the compartment where the secretory and endocytic pathways converge. The TGN is the site where a number of late-Golgi post-translational modifications occur, for example sialylation, tyrosine sulphation and proteolytic processing. In addition, the TGN is the sorting station of the Golgi where proteins are packaged into vesicles and shipped to various destinations, including the cell surface (and either the apical or basolateral surfaces of polarised epithelial cells), lysosomes and secretory storage granules (Farquhar 1985; Griffiths and Simons 1986; Mellman and Simons 1992). Flanked by the CGN and TGN are the cis, medial and trans cisternae, which represent biochemically distinct subcompartments.

Simultaneous localisation of $\mathrm{N}$-acetylglucosaminyltransferase I (GlcNAc-TI) and $\beta 1,4$ GalT by Warren and colleagues (Nilsson et al. 1993a) showed, as was expected, that the two enzymes had different distributions throughout the Golgi stack. However, contrary to the simple models that had been proposed for Golgi compartmentalisation, the results showed that the distributions of the two enzymes were not discrete but overlapped considerably. This was an important observation which was extended in a subsequent study (Rabouille et al. 1995) to include a number of other glycosyltransferases. The overlapping distribution of glycosyltransferases demonstrates that different Golgi compartments have unique mixtures of enzymes rather than different sets of enzymes. A further degree of flexibility is indicated by the differences in the distribution of particular glycosyltransferases between cell types. For example, $\alpha 2,6 \mathrm{ST}$ is found predominantly in the trans region of the Golgi apparatus in hepatocytes and intestinal goblet cells, whereas in absorptive cells from the large intestine $\alpha 2,6 \mathrm{ST}$ is found more extensively distributed throughout the stack (Roth et al. 1985; Taatjes et al. 1988). Collectively, these results demonstrate a certain plasticity in the distribution of glycosylation enzymes throughout the Golgi stack, rather than a strict and discrete compartmentalisation of enzymes. The basis for the differences between cell types is not known but may reflect the underlying dynamic behaviour of Golgi membranes.
How are proteins transported through the Golgi?

Newly synthesised proteins are transported sequentially from the ER to the Golgi and then to their final destination. Until recently it was widely believed that, if correctly folded, newly synthesised proteins were transported from the ER, through the Golgi apparatus without the requirement for a specific transport signal (Pfeffer and Rothman 1987; Rothman and Orci 1992). However, a variety of observations, including electron microscopic data that certain proteins become concentrated as they exit the ER (Balch et al. 1994; Balch and Farquhar 1995), indicate that transport to the Golgi may be mediated by, as yet, undefined transport signals. On the other hand, current evidence indicates that forward transport of newly syntheised proteins through the Golgi apparatus constitutes a signal-independent or default pathway. Despite this extensive flux of proteins, the Golgi apparatus must maintain a set of resident proteins which define its unique structural and functional properties.

How are proteins transferred from one Golgi compartment to the next? A widely held view is that transport vesicles bud from the dilated rims of one cisternae and then target and fuse with the next Golgi compartment (Rothman and Orci 1992; Rothman 1994; Rothman and Warren 1994). Highly defined in vitro reconstitution systems argue for a role of transport vesicles in intra-Golgi transport (Rothman and Orci 1992; Rothman 1994). However, in vivo evidence for intracisternal transport remains largely indirect (Mellman and Simons 1992). Furthermore, it is unclear whether the coated buds associated with the Golgi apparatus represent small vesicles (Orci et al. 1986) or cross-sections through the peripheral tubules of the Golgi (Morré and Keenan 1994). In view of the lack of direct evidence for vesicular transport it is perhaps not surprising that alternative models based on non-vesicular mechanisms of transport are currently attracting renewed attention, in particular, transport by cisternal progression (Mironov et al. 1997) and via membrane tubules (Morré and Keenan 1994; Weidman 1995).

Fundamental to the understanding of membrane transport throughout the Golgi is whether the Golgi subcompartments are indeed physically distinct entities or whether they are continuous. Golgi stacks have been shown to be linked by lateral connections to form a single network (Rambourg and Clermont 1990, 1997). Although transmission electron microscopy indicates that the cisternae of individual stacks are physically distinct entities, by scanning electron microscopy tubular continuities have been observed between cisternae within a stack (Tanaka and Fukudome 1991). Tubular connections between and within stacks could provide structural continuity for non-vesicular transfer of membrane bound and soluble molecules through the Golgi. Clearly, the precise three-dimensional structure of the Golgi warrants further investigation and the relative contribution of vesicular and non-vesicular transport needs to be resolved. This issue is likely to be fundamental for understanding why 
resident Golgi proteins are retained whereas proteins in transit pass through.

\section{Resident Golgi proteins}

The proteins that reside in the Golgi carry out functions associated with post-translational modifications, including glycosylation and proteolytic processing, membrane transport, recycling of ER proteins and maintainance of the structural organisation of the organelle itself. The latter includes proteins involved in the Golgi stacking, interconnections between stacks and the microtubule-dependent positioning of the organelle within the cell. It is not surprising that there are a large number of proteins associated with such diverse functions; these include membrane proteins with single transmembrane domains (both type I and type II membrane orientation), proteins with multiple transmembrane-spanning domains, peripheral membrane proteins and soluble resident Golgi proteins (Fig. 2). Although our understanding of the mechanims of localisation remain in the most cases rudimentary, in view of the diversity of Golgi proteins, one would expect a number of different mechanisms to be operating, as indeed appears to be the case.

Based on biochemical and functional considerations the resident proteins of the Golgi apparatus can be divided into at least seven groups (Table 1). Considerable work has focused on Golgi localisation signals of glycosyltransferases. This is not surprising in view of the key role of the Golgi apparatus in the glycosylation of newly synthesised membrane and secreted proteins (Kornfeld and Kornfeld 1985; Gleeson 1988) and the estimated 100-200 different glycosyltransferase enzymes distributed throughout the Golgi stack. Although individual transferases constitute only a minor percentage of the proteins of the cisternae in which they reside, collectively, the glycosyltransferases of each Golgi cisterna may represent a very significant proportion, if not the bulk, of the resident membrane protein.

The majority of known membrane proteins located in the Golgi stack are type II membrane proteins, with their amino-termini orientated in the cytoplasm and their carboxy-termini in the Golgi lumen. However, there are some exceptions such as the yeast medial-Golgi Emp47 (Schröder et al. 1995), which is a type I membrane protein. The localisation signals of the type II membrane proteins are complex and, in many cases, involve multiple regions of the protein. The dominance of the type II membrane proteins in the Golgi stack contrasts with many of the membrane proteins that reside in the TGN, which have the opposite orientation, namely type I.

In the past few years it has become apparent that there is a distinct set of resident Golgi proteins in the TGN of mammalian cells, and the late Golgi of yeast, that have features associated with their localisation which are distinct from Golgi glycosyltransfeases (Luzio and Banting 1993; Stanley and Howell 1993; Wilsbach and Payne 1993). A characteristic of these TGN proteins is their

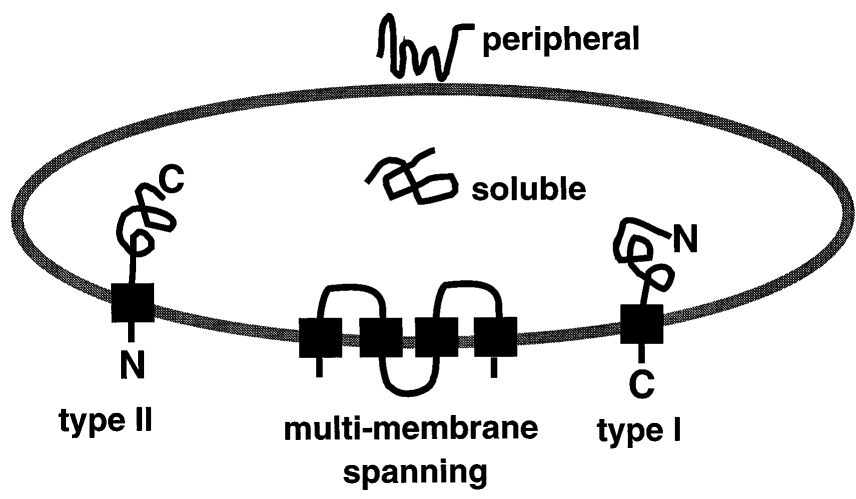

Fig. 2 The different classes of resident Golgi proteins. Resident Golgi proteins include type I and type II membrane proteins, multimembrane-spanning proteins, peripheral membrane proteins and soluble lumenal proteins

ability continuously to recycle between the TGN and post-TGN compartments.

There are a number of multimembrane-spanning proteins which are localised to the Golgi, including viral glycoproteins, retrieval receptors, nucleotide-sugar transporters and the recently described copper translocating P-type ATPase (Petris et al. 1996). A number of peripheral membrane proteins, found on the cytoplasmic surface of Golgi membranes, have been identified, including those considered to be important in the organisation of Golgi membranes and a number implicated in membrane transport. Finally, the first soluble protein localised to the Golgi lumen was described in 1996 (Scherer et al. 1996), raising questions on the retention mechanism of yet another class of resident Golgi protein.

\section{Glycosylation machinery}

Numerous mammalian and yeast Golgi glycosyltransferases, and some processing glycosidases, have been cloned and sequenced (Schachter 1991; Shaper and Shaper 1992; van den Eijnden and Joziasse 1993; Kleene and Berger 1993; Moreman et al. 1994; Field and Wainwright 1995). All are type II membrane proteins. Comparison of the amino acid sequences between these enzymes has revealed very little sequence similarity. This is dramatically illustrated by a lack of obvious amino acid similarity between the sequences of four different GlcNAc transferases involved in the synthesis of the outer antennae of complex $N$-glycans, namely GlcNAc-TI (Kumar et al. 1990; Sarkar et al. 1991), GlcNAc-TII (D’Agostaro et al. 1995), GlcNAc-TIII (Nishikawa et al. 1992) and GlcNAc-TV (Shoreibah et al. 1993). There is, however, an obvious similarity in the domain structure of all Golgi glycosyltransferases. They have a short aminoterminal cytoplasmic domain (many have less than ten amino acids), a single hydrophobic membrane-spanning domain (16-25 amino acids), which also serves as a noncleavable signal sequence, and a large carboxylterminal catalytic domain situated in the lumen of the Golgi appa- 
Table 1 Different classes of proteins localised to the Golgi apparatus

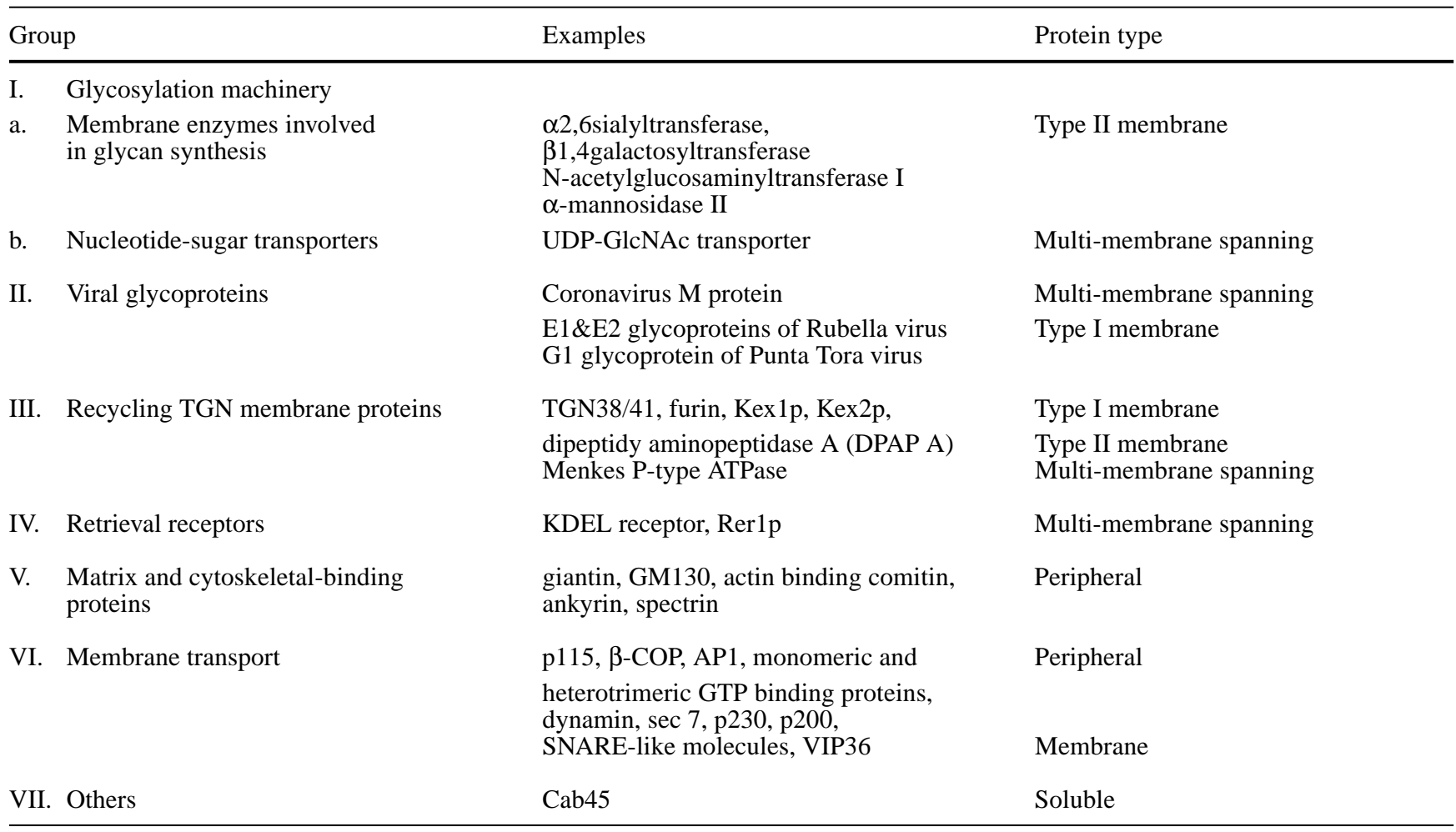

ratus. The catalytic domain is linked to the transmembrane domain by a loosely defined "stem" region which may play a role in positioning the catalytic domain away from the lipid bilayer, facilitating access to the oligosaccharide substrates.

The lack of sequence homology between the different glycosyltransferases suggested from the outset that the Golgi localisation signals were unlikely to be linear amino acid sequence but rather involve structural features associated with conformation.

Other components associated with glycosylation machinery include nucleotide sugar transporters, to transfer the nucleotide-sugars (substrates for the glycosyltransferases) from the cytosol to the Golgi lumen, and nucleoside diphosphatases, which are required to convert the nucleoside diphosphates of the reaction products to nucleotide monophosphates prior to removal from the Golgi lumen. The first Golgi UDP-GlcNAc transporter was recently cloned (Abeijon et al. 1996) and the predicted 328-amino acid protein is a multimembrane-spanning protein with five to eight membrane-spanning domains. Knowledge of the sequence of this transporter now opens the way for the Golgi localisation of this protein to be explored.

\section{Golgi retention sequences of glycosyltransferases}

There has been considerable effort over the past 7 years directed towards the identification of the targeting signals responsible for the localisation of mammalian gly- cosyltransferases. Three mammalian glycosyltransferases have been examined in some detail, namely $\alpha 2,6 \mathrm{ST}$, $\beta 1,4 \mathrm{GalT}$ and GlcNAc-TI; these enzymes are residents predominantly of the TGN (Roth et al. 1985; Taatjes et al. 1988), TGN/trans-Golgi (Roth and Berger 1982; Suganuma et al. 1991; Nilsson et al. 1993a) and medial-Golgi (Dunphy et al. 1985; Burke et al. 1992; Nilsson et al. 1993a), respectively.

The expression of intact glycosyltransferases in transfected mammalian cells results in very efficient Golgi localisation (Munro 1991; Nilsson et al. 1991; Aoki et al. 1992; Burke et al. 1992; Colley et al. 1992; Teasdale et al. 1992). This finding implies that the mechanism to retain glycosyltransferases is very difficult to saturate. The strategy employed to identify putative Golgi retention signal(s) has involved the generation of hybrid or chimeric molecules containing limited sequences derived from Golgi glycosyltransferases fused with a reporter molecule. Analysis of the intracellular location of these hybrid molecules in transfected cells showed the ability of the fusion protein to be retained in the Golgi apparatus. In some but not all cases, putative retention sequences have been replaced in the full-length glycosyltransferases to determine the ability to disrupt Golgi retention. Disruption of the Golgi retention signal is indicated by the appearance of the glycosyltransferase mutants on the cell surface.

In all cases so far examined, the membrane-spanning domains of the mammalian Golgi glycosyltransferases have been shown to direct, at least partial, localisation of hybrid molecules to the Golgi apparatus (Munro 1991; 
Nilsson et al. 1991; Aoki et al. 1992; Russo et al. 1992; Tang et al. 1992; Teasdale et al. 1992; Wong et al. 1992; Burke et al. 1994). Moreover, the transmembrane domain of $\beta 1,4 \mathrm{GalT}$ and GlcNAc-TI can specifically localise hybrid proteins to the trans and medial cisternae, respectively (Nilsson et al. 1991; Burke et al. 1994).

More recently, a number of yeast glycosyltransferases have also been examined which encompass enzymes considered to be localised to the yeast equivalent of either the cis-, medial- or trans-Golgi. These include the initiating $\alpha 1,6$-mannosyltransferase (Och1p) (early-Golgi) (Harris and Waters 1996), $\alpha 1,2$-mannosyltransferase (Mnt1p) (medial-Golgi) (Lussier et al. 1995), and terminal $\alpha 1,3$-mannosyltransferase (Mnn1p) (late-Golgi) (Graham and Krasnov 1995). The transmembrane domains of each of these three glycosyltransferases will also localise (at least partially) heterologous proteins to the yeast Golgi (Chapman and Munro 1994a; Graham and Krasnov 1995; Lussier et al. 1995). This observation, together with the finding that the transmembrane domain of the mammalian $\alpha 2,6 \mathrm{ST}$ can act as a Golgi retention signal in yeast (Schwientek et al. 1995), suggests there is a transmembrane domain-mediated mechanism involved in the retention of Golgi glycosyltransferases in both mammalian cells and yeast.

Although the transmembrane domain is clearly relevant, numerous other studies have revealed that the situation is far more complex than at first appreciated. A large number of constructs of the three mammalian glycosyltransferases have now been examined. However, the results of a number of these studies appear contradictory. Comparison of the results of the different studies is not straightforward as there are a number of factors which may account for the apparent lack of consensus. Differences in results between the different glycosyltransferases may reflect compartment-specific differences; at this stage there is no evidence that glycosyltransferases localised to different compartments are retained by the same mechanism. The lack of agreement between studies on the same glycosyltransferases may be due to: (1) cell type-dependent differences; (2) differences in levels of expression of proteins resulting in differences in intracellular distribution; (3) differences in the precise region of the glycosyltransferase examined, together with the use of different reporter proteins, which may dramatically affect conformation of the segment under study; (4) the use of techniques to monitor localisation which differ widely in sensitivity, especially assessment of cell surface expression; and (5) the presence of more than one region of the glycosyltransferase which can act independently to retain hybrid molecules to the Golgi. Below I will summarise the key findings. For a more detailed comparison of the constructs and discussion of the experimental variables see reviews by Gleeson et al. (1994) and Colley (1997).

A number of investigators have shown that the $\alpha 2,6 \mathrm{ST}$ transmembrane domain and flanking sequences are alone sufficient to localise reporter molecules to the Golgi in certain cell types (Munro 1991; Dahdal and
Colley 1993; Tang et al. 1995). However, it is very clear that Golgi retention does not depend on specific sequences within the transmembrane domain as considerable alterations can be made to the $\alpha 2,6 \mathrm{ST}$ transmembrane domain without abolishing Golgi retention. For example, sequential replacement of four or five amino acid blocks of the transmembrane domain had no effect on Golgi localisation of full-length $\alpha 2,6 \mathrm{ST}$ or an $\alpha 2,6 \mathrm{ST}$ hybrid molecule (Colley et al. 1992; Dahdal and Colley 1993). Strikingly, the transmembrane domain of an $\alpha 2,6 \mathrm{ST}$ hybrid protein (containing the cytoplasmic tail and partial stem of $\alpha 2,6 \mathrm{ST}$ ) can be totally replaced by a polyleucine sequence of similar length without adversely affecting Golgi retention (Munro 1991). Further, Munro (1991) has shown that the length of the hydrophobic transmembrane domain is the critical feature in maintaining efficient Golgi localisation of $\alpha 2,6 \mathrm{ST}$ hybrid molecules as increasing the length of the transmembrane domain to 23 leucine residues resulted in increased expression at the cell surface. The precise relationship between the hydrophobic transmembrane domain and the flanking charged residues appears to be important in retaining $\alpha 2,6$ ST to the TGN (Munro 1991, 1995; Dahdal and Colley 1993). This conclusion is further strengthened by the observation that simply exchanging the transmembrane domains of two cell surface proteins resulted in hybrid proteins which were retarded in transport through the Golgi (Low et al. 1994), indicating that the precise arrangment of the transmembrane domain and flanking sequences may influence exit from the Golgi.

Nonetheless, it is also clear that other regions in addition to the transmembrane domain of $\alpha 2,6 \mathrm{ST}$ play a role in Golgi localisation, in particular the stem region. This conclusion is based on the following observations. Firstly, the stem sequences of $\alpha 2,6 \mathrm{ST}$ improve the Golgi localisation of hybrid molecules (Tang et al. 1995). Secondly, Dahdal and Colley (1993) replaced the 17-amino acid transmembrane domain of native $\alpha 2,6 \mathrm{ST}$ with the long 29-amino acid transmembrane domain from influenza neuraminidase without any apparent disruption of the retention signal, indicating that luminal sequences of $\alpha 2,6 \mathrm{ST}$ can override the length resistrictions of the transmembrane domain. Thirdly, the stem region was demonstrated to be responsible for the transient retention of a soluble form of $\alpha 2,6 \mathrm{ST}$ (Colley et al. 1992).

A number of studies have demonstrated that the localisation of $\beta 1,4 \mathrm{GalT}$ to the trans-Golgi is predominantly dependent on the transmembrane domain (Nilsson et al. 1991; Aoki et al. 1992; Russo et al. 1992; Teasdale et al. 1992, 1994; Masibay et al. 1993), although the cytoplasmic tail and the lumenal domain may play minor roles. As for $\alpha 2,6 \mathrm{ST}$, alterations in the transmembrane domain have not identified a specific sequence that is required for Golgi localisation (Nilsson et al. 1991). There is some evidence from one study that uncharged polar amino acids of the transmembrane domain are important (Aoki et al. 1992), although this remains inconclusive as contrasting results have been obtained from another 
group (Nilsson et al. 1991). Previous studies in this laboratory have demonstrated that replacement of the 20amino acid transmembrane domain of $\beta 1,4 \mathrm{GalT}$ with the longer 27-amino acid transmembrane domain of the transferrin receptor leads to a predominantly cell surface expression in transiently expressing COS cells, whereas stably expressing mouse L cells, where the level of expression is only 2-3 times that of endogenous $\beta 1,4 \mathrm{GalT}$, retain a significant proportion of the hybrid molecules specifically in the Golgi (Teasdale et al. 1994). This result highlights the complications that can arise from differences in the level of expression, and cell type, in the intracellular distribution of a hybrid molecule.

From studies on the localisation of the medial-Golgi enzyme, GlcNAc-TI, it is evident that there are a number of regions which contribute to Golgi localisation. Subsequent to the demonstration that the transmembrane domain of GlcNAc-TI could localise heterologous proteins to the Golgi (Burke et al. 1992; Tang et al. 1992), further analysis showed that the luminal domain and short cytoplasmic tail were required for very efficient Golgi localisation (Burke et al. 1994). The stem sequences of GlcNAc-TI were shown by Tang et al. (1992) to contribute to the efficiency of Golgi localisation of GlcNAc-TI hybrid molecules and more recently by Warren and colleagues (Nilsson et al. 1996) independently to retain a heterologous molecule to the Golgi apparatus. These data argue that the GlcNAc-TI stem region contains a localisation signal independent of the transmembrane domain.

The potential of regions outside the transmembrane domain to assist in Golgi retention is also illustrated by recent studies on yeast Golgi glycosyltransferases. For example, no single domain of Mnt1p was able to confer efficient localisation of a reporter molecule to the yeast Golgi (Lussier et al. 1995); efficient localisation required the short cytoplasmic tail, the transmembrane domain and a segment of the lumenal stem region of Mnt1p, reinforcing the view that multiple signals may be required in some cases. The ability of the lumenal domain to act independently of the transmembrane domain is also highlighted by the observation that the yeast Mnn1p lumenal domain is localised to the Golgi complex even when expressed as a soluble protein (Graham and Krasnov 1995).

Overall, the data suggest that Golgi retention in many instances is not determined by a discrete and continuous sequence motif but, rather, localisation of Golgi glycosyltransferases could be mediated by disparate regions of the molecule. Hence, multiple signals involving cytoplasmic tail, transmembrane and lumenal domains may act together to mediate efficient Golgi localisation. It is noteworthy that the localisation of Sed 5 (Banfield et al. 1994), a putative vesicle targeting molecule, and p63 (Schweizer et al. 1994), both type II membrane proteins of the CGN, involves multiple domains of the molecule including the transmembrane domain. If multiple independent signals act together to mediate efficient Golgi localisation then it is possible that some of these signals may be associated with a saturable mechanism(s) and others, conversely, with a non-saturable mechanism(s) of localisation. For the reasons discussed above, in future it will be important to analyse individual signals using stable expression systems where the level of expression is carefully monitored.

\section{Mechanism of localisation of glycosyltransferases}

As mentioned earlier, overexpression of native glycosyltransferases does not result in saturation of the Golgi retention mechanism. The identification of multiple signals involved in the Golgi retention of glycosyltransferases suggests that there could be more than one mechanism to account for this highly efficient process. One or more of the Golgi retention mechanisms appear to be highly conserved as $\alpha 2,6 \mathrm{ST}$ hybrid molecules are retained in the Golgi apparatus of yeast (Schwientek et al. 1995) and the mammalian enzyme, GlcNAc-TI, appears to be correctly housed in the Golgi apparatus of plant cells (Gomez and Chrispeels 1994).

There are two major models which have been widely discussed to account for compartment-specific localisation of membrane-bound glycosyltransferases, one based on aggregation and the other on lipid-mediated sorting. Both models favour mechanisms in which Golgi glycosyltransferases are prevented from entry into forward moving transport vesicles and thereby are actively retained in one Golgi region.

The aggregation model was first proposed by Machamer (1991), who suggested that glycosyltransferases are induced to form aggregates as they reach the correct Golgi compartment. At the time, Machamer (1991) proposed that the interaction between the transmembrane domains of glycosyltransferase and lipid bilayers of Golgi membranes may be the driving force for oligomerisation. An extension of the aggregation model was put forward by Warren and colleagues (Nilsson et al. 1993b, 1994) who suggested that different enzymes of a particular Golgi compartment interact with each other ("kin recognition") forming large hetero-oligomeric structures which are prevented from entering budding vesicles arising from the dilated rims of the cisternae. It was further speculated that the kin oligomers could be anchored by interaction of their cytoplasmic tails with the Golgi matrix to increase the efficiency of retention (Slusarewicz et al. 1994). The main support for kin recognition comes from the elegant experiments of Nilsson et al. (1994) who showed that the addition of an ER retention motif to the GlcNAc-TI cytoplasmic tail not only causes GlcNAc-TI to localise to the ER but also partially retains another medial-Golgi enzyme, namely $\alpha$-mannosidase II (MannII), within the ER. In contrast, the trans-Golgi enzyme, $\beta 1,4 \mathrm{GalT}$, was not relocated to the ER in these experiments. If interactions between different glycosyltransferases are relevant to Golgi retention the question then arises as to why they are observed in the ER. One possibility is that oligomerisation is a concentration-depen- 
dent process, and the increase in concentration of "tagged" GlcNAc-TI in the ER allows for productive interactions which would normally only take place in the Golgi environment. Support for the presence of kin oligomers within medial-Golgi membranes is suggested by the obervation that GlcNAc-TII, another medial-Golgi enzyme, co-immunoprecipitates with GlcNAc-TI (A. Opat, H. Putalakath and P. Gleeson, unpublished observations).

What is the basis of kin recognition? Using the kin recognition assay of Warren (Nilsson et al. 1994), Munro (1995) demonstrated that the the lumenal domain of GlcNAc-TI, and not the transmembrane domain, was responsible for interaction with MannII. Nilsson et al. (1996) have confirmed and extended this finding and demonstrated that residues 73-103 of the luminal stem region of GlcNAc-TI are important for kin recognition. Mutation of charged residues of this stem region resulted in a dramatic decrease in kin recognition (Nilsson et al. 1996). Furthermore, comparison of the distribution of charged residues in the stem regions of GlcNAc-TI and MannII indicates the potential for charged pairing between these two enzymes that could account for the observed protein oligomerisation.

In addition to the studies described above involving medial-Golgi enzymes, there is also evidence that $\beta 1,4 \mathrm{GalT}$ may also form small oligomers (Teasdale et al. 1994; Yamaguchi and Fukuda 1995), although kin recognition has not been detected for late-Golgi enzymes (Munro 1995). A fundamental issue is whether the formation of homo- or hetero-oligomers is intimately linked with Golgi localisation. Although hetero-oligomerisation is a highly attractive proposition from the viewpoint of the coordination of the glycosylation process, there is no direct evidence at this stage that such interactions are indeed revelant to the Golgi retention of glycosyltransferases. However, the finding that aggregation of avian coronavirus $\mathrm{M}$ protein correlates with Golgi retention (Weisz et al. 1993) and that the retention of p63 to the intermediate compartment depends on the formation of detergent insoluble homo-oligomers (Schweizer et al. 1994), indicates that oligomerisation may be a general mechanism that specifies location of proteins to different compartments.

The lipid-mediated sorting model, proposed by Bretscher and Munro (1993), is based on two observations, namely that the length of the transmembrane domains of Golgi proteins are generally shorter than those of the plasma membrane and that a cholesterol concentration gradient throughout the secretory pathway would result in a lipid bilayer with increasing thickness across the Golgi. Thus, this model proposes that Golgi-resident proteins segregate into different lipid microdomains from the non-resident proteins as a result of differences in the length of their transmembrane segments (Bretscher and Munro 1993). Experimental evidence for this model comes from the finding that the length of the transmembrane domain of $\alpha 2,6 \mathrm{ST}$ in important in retention (Munro 1991). A difficulty with this model is that a number of
Golgi glycosyltransferases, for example GlcNAc-TI, have transmembrane domains of similar length to cell surface proteins, and that regions other than the transmembrane domain can act as independent retention signals in a number of cases.

The two models described above are not mutually exclusive and both mechanisms may contribute to different extents, depending on the protein and the targeted compartment (Munro 1995). Nonetheless, it is now becoming very clear that these two models cannot fully explain the basis for Golgi localisation of glycosyltransferases. Lippincott-Schwartz and colleagues (Cole et al. 1996) have measured the diffusional mobility of $\beta 1,4 \mathrm{GalT}$ and MannII, tagged with a green fluorescent protein in mammalian cells, and have shown that the green fluorescent chimeric proteins could diffuse rapidly and freely in Golgi membranes, indicating that Golgi targeting and retention does not depend on protein immobilisation. If these findings are extended to other glycosyltransferases then models involving retention via mechanisms invoking protein immobilisation within Golgi membranes would seem unlikely.

Another possibility is that recycling may contribute to localisation. Although recycling of $\alpha 2,6 \mathrm{ST}$ and $\beta 1,4$ GalT from post-Golgi membranes is unlikely (Wong et al. 1992; Chapman and Munro 1994b; Teasdale et al. 1994), there is some support for the possibility of intraGolgi recycling. For example, the localisation of the cisGolgi yeast mannosyltransferase, Och1p, appears to involve retrieval from a more distal Golgi compartment (Harris and Waters 1996), rather than active retention in the cis-Golgi. In addition, there is also evidence that GlcNAc-TI may recycle between the cis- and medial-Golgi cisternae in a mutant $\mathrm{CHO}$ cell line (Hoe et al. 1995). The sialylation of the medial-Golgi membrane protein, MG160, has been suggested to result from retrograde transport from the TGN to the medial-Golgi (Johnson et al. 1994). More information on intra-Golgi recycling and the potential of retrieval in the localisation of other glycosyltransferases needs to be more fully explored.

Overall, the specific localisation of Golgi glycosyltransferases is clearly complex. Aggregation, lipid bilayer mediated sorting and intra-Golgi retrieval may all act to play a role in retention. The relative importance of each of these components may differ between compartments. A limiting factor in our understanding of Golgi retention is the lack of information about the behaviour of glycosyltransferases in Golgi membranes. The localisation of a particular glycosyltransferase is a reflection of its steady-state distribution. In turn, the steady-state distribution of a glycosyltransferase in the Golgi may well be a combination of a number of factors, including the degree of aggregation, coupled with the rate of forward transport (either by vesicular transport or through connecting tubules), together with the efficiency of retrograde transport.

Collectively, these processes may also be fundamental for the structural maintenance of Golgi membranes. Modifications of the transmembrane domain of GlcNAc- 
TI resulted in the loss of stack structure and an abundance of tubulo-vesicular clusters which contained the mutant GlcNAc-TI molecules (Nilsson et al. 1996). In another study, these investigators noted that relocation of medial-Golgi enzymes to the ER perturbed the structure of the stack (Nilsson et al. 1994). Also noteworthy is the finding that a number of yeast mutants, which fail to retain Mnt1p hybrid molecules to the Golgi, appear to have defects associated with the organisation of the Golgi (Chapman and Munro 1994a). As proteins can play a major role in defining the structure of an organelle, as demonstrated by the de novo formation of caveolae in lymphocytes by the expression of the protein caveolin (Fra et al. 1995), it is conceivable that glycosyltransferases may contribute significantly to the formation of the typical cisternae structure of Golgi membranes. Thus, understanding retention of Golgi glycosyltransferases may well be intimately linked to understanding the biogenesis of Golgi membranes.

\section{Golgi-localised viral proteins}

A number of viruses from the coronavirus, bunyavirus and togavirus families acquire their envelopes by budding into Golgi membranes (Pettersson 1991; Griffiths and Rottier 1992; Hobman 1993). Viral budding from the Golgi apparatus is determined by the targeting of one or more viral glycoproteins to the Golgi membranes. Various viral proteins have been shown to be independently targeted to the Golgi apparatus, including the M (membrane) proteins of an avian coronavirus (Machamer et al. 1990) and a related murine coronavirus (Armstrong et al. 1987; Krijnse Locker et al. 1992), the E2 spike glycoprotein of rubella virus (Hobman et al. 1993) and the G1 glycoproteins of Punta Tora virus (Chen et al. 1991) and of Uukuniemi virus (Melin et al. 1995). Viral proteins targeted to the Golgi include both type I membrane and multimembrane-spanning proteins (Table 1). Some of these viral proteins have been shown to be targeted to different Golgi compartments. For example, the M protein of the avian coronovirus, IBV, has been shown to be localised specifically to the cis-Golgi cisternae (Machamer et al. 1990), whereas the M protein of the coronavirus mouse hepatitis virus (MHV) is targeted to the TGN when expressed from cDNA (Krijnse Locker et al. 1992). As a consequence of the specific localisation of these viral glycoproteins they are very useful tools to study retention of resident Golgi proteins.

As for Golgi glycosyltransferases, transmembrane domains of a number of Golgi-localised viral proteins have been shown to play a crucial role in localisation (Swift and Machamer 1991; Krijnse Locker et al. 1994b; Matsuoka et al. 1994; Hobman et al. 1995 ); in some cases the cytoplasmic tail is also essential for efficient Golgi retention (Krijnse Locker et al. 1994b; Matsuoka et al. 1994).

The $\mathrm{M}$ proteins of coronaviruses contain three membrane-spanning domains, a short glycosylated amino-terminal domain and a carboxy-terminal cytoplasmic tail.
The first of the three membrane-spanning domains of the $\mathrm{M}$ protein of IBV is required to retain this protein in the Golgi (Machamer and Rose, 1987). Furthermore, this membrane-spanning domain is sufficient to confer Golgi localisation upon a plasma membrane-localised protein (Swift and Machamer 1991). In contrast to the findings for the M protein of IBV, Krijnse Locker et al. (1994b) demonstrated that two signals are required for the Golgi localisation of MHV M protein, namely one contained within a transmembrane domain and one within the cytoplasmic tail. As the MHV M protein is targeted to the TGN, and the IBV M protein to the cis-Golgi, the different locations of these coronovirus $M$ proteins may account for the difference in targeting signals.

Extensive mutagenesis has identified features of the transmembrane domain of IBV $\mathrm{M}$ protein that may be important for localisation. Four polar residues in the first IBV M transmembrane domain are critical for Golgi retention of a reporter molecule (Machamer et al. 1993). These four polar residues are predicted to form an uncharged polar face along one side of an $\alpha$-helix. Likewise, alterations to the predicted polar face of the transmembrane domain $\alpha$-helix of Punta Toro virus G1 glycoprotein also perturbed Golgi localisation and resulted in partial expression of this protein on the cell surface (Matsuoka et al. 1996). The uncharged polar face of the $\alpha$-helix may promote protein-protein interactions and thereby mediate oligomer formation.

There is evidence that aggregation may be important in Golgi retention of coronavirus $M$ proteins. For instance, aggregation has been shown to correlate with retention of an IBV M hybrid protein in the Golgi apparatus (Weisz et al. 1993). These investigators demonstrated that the appearance of SDS-resistant aggregates of an M hybrid protein correlated with Golgi localisation, whereas mislocalised transmembrane domain mutants do not oligomerise. However, SDS-resistant oligomers of the intact $\mathrm{M}$ protein were not detected in this study (Weisz et al. 1993), thus the relationship between aggregate formation of the $\mathrm{M}$ hybrid molecule and Golgi retention of the native $M$ protein remains unclear. On the other hand, Krijnse Locker et al. (1995) have demonstrated that newly synthesised MHV M protein in the ER or intermediate compartment exists essentially as a monomer, however, MHV M protein formed large detergent-insoluble complexes following arrival in the Golgi apparatus. The behaviour of mutant proteins suggested that the self-association of MHV M protein may be mediated by the transmembrane domain, whereas the cytoplasmic tail, which is also required for Golgi localisation, could be required to interact with components of the TGN to immobilise the oligomers. These results not only reinforce the potential importance of aggregation in the localisation of Golgi membrane proteins but also highlight the possibility that multiple retention mechanisms are operating. 


\section{Recycling membrane proteins of the TGN}

In contrast to the complex retention signals of Golgi glycosyltransferases, the retention signals of a class of membrane proteins in the TGN are becoming well defined. This group includes mammalian TGN proteins as well as membrane proteins in the late Golgi of yeast, considered to be functionally equivalent to the TGN of animal cells (Wilsbach and Payne 1993). This group of TGN proteins shares the following characteristics: (1) ability to recycle from post-Golgi compartments; (2) retention signals located within their cytoplasmic tails; (3) a TGN localisation which can be saturated; and (4) in many cases, a type I membrane orientation.

This group includes the mammalian proteins TGN38 (and the isoform TGN41) (Stanley and Howell 1993), furin (Molloy et al. 1994), Menkes P-type ATPase (Petris et al. 1996) and varicella-zoster virus glycoprotein I (gpI) (Alconada et al. 1996; Zhu et al. 1996), as well as the yeast proteolytic enzymes Kex $1 p, \operatorname{Kex} 2 p$ and dipeptidylaminopeptidase A (DPAP A) (Nothwehr and Stevens 1994). In contrast to the Golgi glycosyltransferases, TGN38, furin, gpI, Kex1p and Kex2p are type I membrane proteins, however, membrane orientation is not an absolute characteristic of the group as DPAP A is a type II membrane protein and Menkes P-type ATPase is a multimembrane-spanning protein. The mannose-6-phosphate receptors share some of the properties of this Golgi resident group, however, as the bulk of these receptors appears to be found in an endosome compartment and not the TGN, these receptors will not be included in this discussion (Kornfeld 1992).

The functions of these mammalian TGN molecules are diverse. Furin belongs to a family of subtilisin-related mammalian endoproteases (Barr et al. 1991), TGN38 may be involved in the formation of exocytic vesicles from the TGN (Luzio et al. 1990; Reaves et al. 1992; Jones et al. 1993; Stanley and Howell 1993) and Menkes P-type ATPase is a copper translocating pump involved in copper efflux (Camakaris et al. 1995). At steady state these proteins are found predominantly in the TGN. However, overexpression of furin (Takahashi et al. 1995), TGN38 (Reaves and Banting 1994) and gpI (Alconada et al. 1996) results in detection of the proteins at the cell surface, indicating that the mechanism of TGN localisation can be saturated. Furthermore, numerous studies have shown that all these proteins continuously recycle between the TGN, endosomes and the cell surface. For example, antibody uptake experiments and the use of drugs which inhibit endosomal recycling, such as chloroquine or bafilomycin A1, have shown that furin (Chapman and Munro 1994b; Molloy et al. 1994), TGN38 (Ladinsky and Howell 1992; Bos et al. 1993; Reaves et al. 1993), gpI (Alconada et al. 1996) and Menkes P-type ATPase (Petris et al. 1996) are internalised from the cell surface and returned to the TGN via endosomes. On the other hand, the pathway that these TGN residents follow on the way to the cell surface is not so well characterised; it may involve transit through an en- dosome and/or direct transport to the cell surface (see Takahashi et al. 1995).

The recycling of these proteins is likely to be linked to their function, however, at this stage the biological relevance of the intracellular trafficking of TGN38 and furin is unclear. The recycling of Menkes protein appears to be intimately associated with its function in copper efflux; when cells are subjected to elevated copper levels the intracellular distribution of the protein is dramatically altered, with a decrease in the TGN pool and an increase in the pool at the cell surface (Petris et al. 1996). The increased trafficking of the Menkes protein to the cell surface is associated with the removal of intracellular copper.

Although these Golgi proteins continuously recycle between the TGN and the plasma membrane, there clearly has to be a mechanism for retaining the bulk of these molecules in the TGN. Presumably exit from the TGN is the rate limiting step in recycling. The cytoplasmic domains of TGN 38 (Bos et al. 1993; Humphrey et al. 1993; Wong and Hong 1993), furin (Chapman and Munro 1994b; Molloy et al. 1994) and gpI (Alconada et al. 1996; Zhu et al. 1996) have been shown to mediate TGN localisation and internalisation from the plasma membrane. A tyrosine-based tetrapeptide motif, YXXZ ( $\mathrm{Y}$ is tyrosine, $\mathrm{X}$ is any amino acid and $\mathrm{Z}$ is a hydrophobic residue), in the cytoplasmic tails of TGN38 (Bos et al. 1993; Humphrey et al. 1993; Wong and Hong 1993), furin (Jones et al. 1995; Schafer et al. 1995; Takahashi et al. 1995; Voorhees et al. 1995), and gpI (Alconada et al. 1996) has been shown to be important in their localisation. YXXZ-type signals are capable of mediating rapid internalisation at the plasma membrane through coated pits into endosomes (Trowbridge et al. 1993). In addition to the YXXZ signal a second, novel, signal involving a cluster of acidic amino acids has been identified in the cytoplasmic domain of furin (Schafer et al. 1995; Voorhees et al. 1995) and gpI (Alconada et al. 1996; Zhu et al. 1996). This latter signal may also control endocytosis and recycling back to the TGN (Voorhees et al. 1995; Alconada et al. 1996) and, in the case of furin, has also been reported to act as the dominant signal for TGN localisation (Schafer et al. 1995; Voorhees et al. 1995). The acidic cluster of both furin (Jones et al. 1995; Takahashi et al. 1995) and gpI (Alconada et al. 1996) includes potential casein kinase II phosphorylation sites. In furin these sites have been demonstrated to be phoshorylated in vitro by casein kinase II (Jones et al. 1995; Takahashi et al. 1995) and in vivo (Jones et al. 1995). Mutation of the potential phosphorylation sites in gpI (Alconada et al. 1996) and furin (Takahashi et al. 1995) results in a dramatic alteration of the intracellular distribution of the protein. Hence, the intracellular trafficking of furin and gpI may be modulated by the phosphorylation state.

There are a number of differences in the nature of the targeting signals of furin and TGN38. Firstly, in constrast to furin, TGN38 lacks an acidic cluster signal. However, the tyrosine-based motif of TGN38 (SDYQRL) ap- 
pears capable of not only mediating the internalisation of TGN38 from the cell surface but also the trafficking of internalised TGN38 to the TGN. For example, mutation of the YQRL sequence to YQDL abrogated TGN localistion of TGN 38 but did not affect internalisation (Humphrey et al. 1993). Thus, the precise context of the YXXZ motif may provide specificity for intracellular targeting to the TGN (Marks et al. 1997). In addition, the transmembrane domain of TGN38 appears to also contribute to TGN localisation (Ponnambalam et al. 1994), whereas this is not the case for furin (Schafer et al. 1995). Similar trafficking pathways of furin and TGN38 may therefore be mediated by different sets of signals. The cytoplasmic domain of Menkes P-type ATPase contains a number of potential signals, including multiple tyrosine-based motifs, dileucine motifs and an acidic cluster, however, the relative importance of each in localisation and trafficking of this protein is not known (Petris et al. 1996).

The yeast proteins DPAP A, Kex $2 p$ and Kex $1 p$ are all integral membrane proteins with cytoplasmic tails of about 100 amino acids. These cytoplasmic tails are required for retention of these enzymes in the late Golgi since deletions in the tail reduce the efficiency of retention (Cooper and Bussey 1992; Wilcox et al. 1992; Nothwehr et al. 1993). Aromatic-based Golgi localisation signals have been identified within the cytoplasmic tails of Kex $2 p$ and DPAP A which are very similar to the general motif for clustering into clathrin-coated pits of animal cells (Wilcox et al. 1992; Nothwehr et al. 1993). Deletion of the Golgi retention signal, or overexpression of these proteins, results in mislocalisation to the vacuolar compartment. This initially surprising finding leads to the conclusion that the default destination for membrane proteins in the yeast secretory pathway is the vacuolar compartment and not the plasma membrane.

Studies on the yeast class E vacuolar protein sorting (vps) mutants suggest that DPAP A may leak from the late Golgi and is transported, via the default pathway, to a post-Golgi/pre-vacuolar compartment (Nothwehr and Stevens 1994). The aromatic-based motif in the cytoplasmic domain of these escaped DPAP A molecules then mediates retrieval back to the late Golgi; in the absence of the cytoplasmic tail Golgi localisation signals, these membrane proteins would continue to be transported along this default pathway to vacuoles. Loss of the clathrin heavy chain gene, $\mathrm{CHC1}$, in yeast results in mislocalisation of Kex $2 p$ and DPAP A, indicating clathrin is necessary for either retention of these proteins in the TGN or recycling from the prevacuolar compartment back to the TGN (Seeger and Payne 1992a, b; Wilsbach and Payne 1993).

Recently, Bryant and Stevens (1997) identified a second independent localisation signal in the cytoplasmic tail of DPAP A by employing an assay which uncoupled retrieval-based localisation from active Golgi retention. These investigators have proposed that this second signal slows the rate of exit at the TGN whereas the aromatic motif directs retrieval from the prevacuolar compartment.
A large group of novel Saccharomyces cerevisiae mutants have been generated which are Golgi Retention Defective ( $g r d$ ) (Nothwehr et al. 1996). Many of these mutants appear to be specifically defective in the retention of DPAP A and Kex $2 p$ and therefore should prove useful in defining the machinery involved in Golgi retention of this class of TGN protein.

TGN recycling proteins share the same Golgi compartment as the glycosyltransferases $\alpha 2,6 \mathrm{ST}$ and $\beta 1,4 \mathrm{GalT}$. Although the recycling of furin and TGN38 clearly demonstrates that an efficient pathway exists for the recapture of TGN proteins from the cell surface of mammalian cells, experimental data argue against the recycling of $\alpha 2,6 \mathrm{ST}$ and $\beta 1,4 \mathrm{GalT}$ from post-Golgi compartments (Wong et al. 1992; Chapman and Munro 1994b; Teasdale et al. 1994), nonetheless these glycosyltransferases are very efficiently retained within the Golgi. Thus there are two sets of membrane proteins within the same Golgi compartment with very different mechanisms of localisation. Clearly we need to understand why some TGN-localised proteins can enter exocytic vesicles more efficiently than others. One possibility is that the TGN consists of distinct membrane subdomains (Ladinsky et al. 1994) with the two classes of resident proteins localised to separate subdomains.

\section{Other Golgi-resident proteins}

Other groups of Golgi-resident proteins include retrieval receptors, matrix and cytoskeletal-binding proteins and components of the vesicular transport machinery (Table 1).

A number of ER proteins are retrieved from the Golgi apparatus by the interaction with specific receptors followed by retrograde transport to the ER. These include the multimembrane-spanning KDEL/HDEL receptor, which resides predominantly in the early Golgi but is also found throughout the Golgi stack (Lewis and Pelham 1992; Tang et al. 1993). As KDEL receptors only recycle back to the ER after binding to ligand (Lewis and Pelham 1992), this receptor is likely to have signals for Golgi localisation, however, the nature of these signals is not known. The retrieval of Sec12p from the Golgi to the ER in yeast is mediated by the Golgi-localised multimembrane-spanning Rer1p (Sato et al. 1995, 1996). Although the precise role of Rer1p in the recycling process of Sec12p is not clear, in view of the previous discussion on glycosyltransferases, it is of particular interest that the Rerlp dependent retrieval mechanism requires the transmembrane domain of Sec12p (Boehm et al. 1994; Sato et al. 1996). This finding raises the possibility that transmembrane domain-mediated retention may involve an interaction with sorting and/or retrieval receptors.

A number of Golgi matrix proteins have been described, including giantin (Linstedt and Hauri 1993) and GM130 (Nakamura et al. 1995), as well as Golgi-localised cytoskeletal-associated proteins such as the dynein heavy chain isoform DHC2 (Vaisberg et al. 1996), the actin-binding protein comitin (Weiner et al. 1993; Jung 
et al. 1996) and isoforms of ankyrin (Devarajan et al. 1996) and spectrin (Beck et al. 1994). Again, the basis of Golgi residency of these protein has not been defined.

Numerous proteins associated with the machinery of vesicular transport are localised specifically (or are enriched) on Golgi membranes, for example $\beta$-COP (Oprins et al. 1993; Griffiths et al. 1995), the monomeric GTPases rab6 (Gould et al. 1990) and ypt31p/32p (Benli et al. 1996), heterotrimeric G proteins (Stow et al. 1991; Pimplikar and Simons 1993), dynamin (Henley and McNiven 1996), AP-1 adaptors (Pearse and Robinson 1990), p230 (Kooy et al. 1991; Gleeson et al. 1996), p200 (Narula et al. 1992; Narula and Stow 1995), sec 7 (Franzusoff et al. 1991), SNARE-like molecules (Banfied et al. 1995; Subramaniam et al. 1996) and VIP36 (Fiedler et al. 1994) (Table 1). Many of these are peripheral membrane proteins associated with the cytosolic face of Golgi membranes which recycle between a cytosolic pool and Golgi membranes. In some cases, for example COPI and AP1 adaptor, there is evidence that the proteins interact with motifs on the cytoplasmic domains of membrane proteins (see review by Robinson 1997). Other components have complex intracellular locations perhaps due to membrane trafficking back and forth from the Golgi. The identification of the precise nature of the targeting signals and the mechanism of localisation of these periperal and membrane proteins will be important to the understanding of the organisation of the Golgi apparatus and vesicular transport.

\section{Concluding remarks: the way forward}

In the past decade, many resident Golgi proteins have been defined and some progress made toward understanding the molecular basis of Golgi localisation. Overall, the situation is highly complex. Firstly, there are a number of distinct groups of Golgi-resident proteins; secondly, from studies on glycosyltransferases and recycling TGN proteins, it is clear that the localisation of individual proteins can involve multiple signals; thirdly, the localisation of Golgi glycosyltransferases and recycling TGN proteins could involve more than one mechanism; and fourthly, there is increasing evidence that resident Golgi proteins are involved in maintenance of the Golgi structure itself.

Although much has been learnt from the localisation of chimeric glycosyltransferase molecules, the approaches remain relatively crude. The systems need to be better defined to analyse single localisation sequences using systems which uncouple the potential retention mechanisms, i.e. oligomerisation from intra-Golgi recycling. More information is required about the precise organisation of enzymes within Golgi membranes and their possible interactions with other components of glycosylation machinery such as nucleotide-sugar transporters, and with molecules that may be important in mediating retention. In addition, the conditions which induce aggregation of glycosyltransferase need to be identified and the precise role of kin recognition in the localisation process defined. Further, the role of the transmembrane domain of glycosyltransferase in localisation, either by lipid-mediated sorting or through interactions with sorting proteins, needs to be clarified.

Knowledge of Golgi retention and biogenesis of Golgi membranes requires a combined biochemical and genetic approach. Yeast vps and grd mutants will continue to provide insight into the nature of the components involved in the retention machinery and recycling of TGN proteins and the identification of common localisation mechanisms. However, there is increasing evidence that Golgi retention is intimately associated with maintenance of membrane structure and a major drawback of Saccharomyces is the poor morphology of the Golgi apparatus. Genetically manipulable systems are required where Golgi structure can be readily monitored. Protozoan parasites may provide a very useful model system as the Golgi structure is highly developed in a number of these eukaryotic parasites and, furthermore, in some parasites, for example Leishmania and Giardia, the induction of Golgi structure is developmentally regulated (Pimenta et al. 1991; Winter et al. 1994; Luján et al. 1995). Thus, these organisms offer the potential to understand the biogenesis of Golgi membranes.

Acknowledgements This work was supported by grants from the National Health and Medical Research Council of Australia and the Australian Research Council. I would like to thank Andrew Opat for helpful comments on the manuscript.

\section{References}

Abeijon C, Robbins PW, Hirschberg CB (1996) Molecular cloning of the Golgi apparatus uridine diphosphate- $N$-acetylglucosamine transporter from Kluyveromyces lactis. Proc Natl Acad Sci USA 93:5963-5968

Alconada A, Bauer U, Hoflack B (1996) A tyrosine-based motif and a casein kinase II phosphorylation site regulate the intracellular trafficking of the varicella-zoster virus glycoprotein I, a protein localized in the trans-Golgi network. EMBO J 15:6096-6110

Aoki D, Lee N, Yamaguchi N, Dubois C, Fukuda MN (1992) Golgi retention of a trans-Golgi membrane protein, galactosyltransferase, requires cysteine and histidine residues within the membrane-anchoring domain. Proc Natl Acad Sci USA 89:4319-4323

Armstrong J, McCrae M, Colman A (1987) Expression of coronavirus E1 and rotavirus VP110 membrane proteins from synthetic RNA. J Cell Biochem 35:129-136

Balch WE, Farquhar MG (1995) Beyond bulk flow. Trends Cell Biol 5:16-19

Balch WE, McCaffery JM, Plutner H, Farquhar MG (1994) Vesicular stomatitis virus glycoprotein is sorted and concentrated during export from the endoplasmic reticulum. Cell 76:841852

Banfield DK, Lewis MJ, Rabouille C, Warren G, Pelham HRB (1994) Localization of Sed5, a putative vesicle targeting molecule, to the cis-Golgi network involves both its transmembrane and cytoplasmic domains. J Cell Biol 127:357-371

Banfied DK, Lewis MJ, Pelham HRB (1995) A SNARE-like protein required for traffic through the Golgi complex. Nature 375:806-809

Barr PJ, Mason OB, Landsberg PA, Wong MC, Kiefer MC, Brake AJ (1991) cDNA and gene structure for a human subtilisin- 
like protease with cleavage specificity for paired basic amino acid residues. DNA Cell Biol 10:319-328

Beck KA, Buchanan JA, Malhotra V, Nelson WJ (1994) Golgi spectrin: identification of an erythroid beta-spectrin homolog associated with the Golgi complex. J Cell Biol 127:707-723

Benli M, Döring F, Robinson DG, Yang X, Gallwitz D (1996) Two GTPase isoforms, Ypt31p and Ypt32p, are essential for Golgi function in yeast. EMBO J 15:6460-6475

Boehm J, Ulrich HD, Ossig R, Schmitt HD (1994) Kex2-dependent invertase secretion as a tool to study the targeting of transmembrane proteins which are involved in ER $\rightarrow$ Golgi transport in yeast. EMBO J 13:3696-3710

Bos K, Wraight C, Stanley KK (1993) TGN38 is maintained in the trans-Golgi network by a tyrosine-containing motif in the cytoplasmic domain. EMBO J 12:2219-2228

Bretscher MS, Munro S (1993) Cholestrol and Golgi apparatus. Science 261:1280-1281

Bryant NJ, Stevens TH (1997) Two separate signals act independently to localize a yeast late Golgi membrane protein through a combination of retrieval and retention. $J$ Cell Biol 136:287-297

Burke J, Pettitt JM, Schachter H, Sarkar M, Gleeson PA (1992) The transmembrane and flanking sequences of beta-1,2- $N$-acetylglucosaminyltransferase I specify medial-Golgi localization. J Biol Chem 267:24433-24440

Burke J, Pettitt JM, Humphris D, Gleeson PA (1994) Medial-Golgi retention of $\mathrm{N}$-acetylglucosaminyltransferase I. J Biol Chem 269:12049-12059

Camakaris J, Petris MJ, Bailey L, Shen P, Lockhart P, Glover TW, Barcroft CL, Patton J, Mercer JFB (1995) Gene amplification of the Menkes (MNK; ATP7A) P-type ATPase gene of CHO cells is associated with copper resistance and enhanced copper efflux. Hum Mol Genet 4:2117-2123

Chapman RE, Munro S (1994a) The functioning of the yeast Golgi apparatus requires an ER protein encoded by ANP1, a member of a new family of genes affecting the secretory pathway. EMBO J 13:4896-4907

Chapman RE, Munro S (1994b) Retrieval of TGN proteins from the cell surface requires endosomal acidification. EMBO J 13:2305-2312

Chen SY, Matsuoka Y, Compans RW (1991) Golgi complex localization of the Punta Toro virus G2 protein requires its association with the G1 protein. Virology 183:351-365

Cole NB, Smith CL, Sciaky N, Terasaki M, Edidin M, LippincottSchwartz J (1996) Diffusional mobility of Golgi proteins in membranes of living cells. Science 273:797-801

Colley K (1997) Golgi localization of glycosyltransferases: more questions than answers. Glycobiology 7:1-13

Colley KJ, Lee EU, Paulson JC (1992) The signal anchor and stem regions of the beta-galactoside alpha-2,6-sialyltransferase may each act to localize the enzyme to the Golgi apparatus. J Biol Chem 267:7784-7793

Cooper A, Bussey H (1992) Yeast Kex2 is a Golgi-associated membrane protein: deletions in a cytoplasmic targeting domain result in mislocalization to the vacuolar membrane. J Cell Biol 119:1459-1468

D’Agostaro GAF, Zingoni A, Moritz RL, Simpson RJ, Schachter $\mathrm{H}$, Bendiak B (1995) Molecular cloning and expression of cDNA encoding the rat UDP- $N$-acetylglucosamine:alpha-6-Dmannoside beta-1,2- $N$-acetylglucosaminyltransferase II. J Biol Chem 270:15211-15221

Dahdal RY, Colley KJ (1993) Specific sequences in the signal anchor of the beta-galactoside alpha-2,6-sialytransferase are not essential for Golgi localization. J Biol Chem 268:26310 26319

Devarajan P, Stabach PR, Mann AS, Ardito T, Kashgarian M, Morrow JS (1996) Identification of a small cytoplasmic ankyrin (AnkG119) in the kidney and muscle that binds bI* spectrin and associates with the Golgi apparatus. J Cell Biol 133:819-830

Dunphy WG, Rothman JE (1983) Compartmental organisation of the Golgi stack. Cell 42: 13-21
Dunphy WG, Brands R, Rothman JE (1985) Attachment of terminal $\mathrm{N}$-acetylglucosamine to asparagine-linked oligosaccharides occurs in central cisternae of the Golgi stack. Cell 40:463-472

Eijnden DH van den, Joziasse DH (1993) Enzymes associated with glycosylation. Curr Opin Struct Biol 3:711-721

Farquhar MG (1985) Progress in unravelling pathways of Golgi traffic. Annu Rev Cell Biol 1:447-488

Farquhar MG, Palade GE (1981) The Golgi apparatus (complex)(1954-1981)-from artifact to center stage. J Cell Bio $91: 77 \mathrm{~s}-103 \mathrm{~s}$

Fiedler K, Parton RG, Kellner R, Etzold T, Simons K (1994) VIP36, a novel component of glycolipid rafts and exocytic carrier vesicles in epithelial cells. EMBO J 13:1729-1740

Field MC, Wainwright LJ (1995) Molecular cloning of eukaryotic glycoprotein and glycolipid glycosyltransferases: a survey. Glycobiology 5:463-472

Fleischer B, Fleischer S, Ozawa H (1969) Isolation and characterization of Golgi membranes from bovine liver. J Cell Biol 43:59-79

Fra AM, Williamson E, Simons K, Parton RG (1995) De novo formation of caveolae in lymphocytes by expression of VIP21-caveolin. Proc Natl Acad Sci USA 92:8655-8659

Franzusoff A, Redding K, Crosby J, Fuller RS, Schekman R (1991) Localization of components involved in protein transport and processing through the yeast Golgi apparatus. J Cell Biol 112:27-37

Gleeson PA (1988) Complex carbohydrates of plants and animals a comparison. Curr Top Microbiol Immunol 139:1-34

Gleeson PA, Teasdale RD, Burke J (1994) Targeting of proteins to the Golgi apparatus. Glycoconj J 11:381-394

Gleeson PA, Anderson TJ, Stow JL, Griffiths G, Toh BH, Matheson $\mathrm{F}$ (1996) p230 is associated with vesicles budding from the trans-Golgi network. J Cell Sci 109:2811-2821

Goldberg DE, Kornfeld S (1983) Evidence for extensive subcellular organisation of asparagine-linked oligosaccharide processing and lysosomal enzyme phosphorylation. J Biol Chem $258 \cdot 3159-3165$

Golgi C (1893) Sur la fine organisation des glandes peptiques des mammiféres. Arch Ital Biol 19:448-453

Golgi C (1898) Sur la structure des cellules nerveuses. Arch Ital Biol 30:60-71

Gomez L, Chrispeels MJ (1994) Complementation of an Arabidopsis thaliana mutant that lacks complex asparagine-linked glycans with the human cDNA encoding $N$-acetylglucosaminyltransferase I. Proc Natl Acad Sci USA 91:1829-1833

Gould B, Zahraoui A, Tavitian A, Saraste J (1990) Small GTP-binding protein associated with Golgi cisternae. Nature 345:553-556

Graham TR, Krasnov VA (1995) Sorting of yeast $\alpha-1,3-$ mannosyltransferase is mediated by a lumenal domain interaction, and a transmembrane domain signal that can confer clathrin-dependent Golgi localization to a secreted protein. Mol Biol Cell 6:809-824

Griffiths G, Rottier P (1992) Cell biology of viruses that assemble along the biosynthetic pathway. Semin Cell Biol 3:367-381

Griffiths G, Simons K (1986) The trans-Golgi network: sorting at the exit site of the Golgi complex. Science 234:438-443

Griffiths G, Pepperkok R, Locker JK, Kreis TE (1995) Immunocytochemical localization of beta-COP to the ER-Golgi boundary and the TGN. J Cell Sci 108:2839-2856

Harris SL, Waters MG (1996) Localization of a yeast early Golgi mannosyltransferase, Och1p, involves retrograde transport. J Cell Biol 132:985-998

Hauri H-P, Schweizer A (1992) The endoplasmic reticulum-Golgi intermediate compartment. Curr Opinion Cell Biol 4:600-608

Henley JR, McNiven MA (1996) Association of a dynamin-like protein with the Golgi apparatus in mammalian cells. J Cell Biol 133:761-775

Hobman TC (1993) Targeting of viral glycoproteins to the Golgi complex. Trends Microbiol 4:124-130

Hobman TC, Woodward L, Farquhar MG (1993) The rubella virus E2 and E1 spike glycoproteins are targeted to the Golgi complex. J Cell Biol 121:269-281 
Hobman TC, Woodward L, Farquhar MG (1995) Targeting of a heterodimeric membrane protein complex to the Golgi: rubella virus E2 glycoprotein contains a transmembrane Golgi retention signal. Mol Biol Cell 6:7-20

Hoe MH, Slusarewicz P, Misteli T, Watson R, Warren G (1995) Evidence for recycling of the resident medial/trans-Golgi enzyme, $\mathrm{N}$-acetyglucosaminyltransferase I, in IdlD cells. J Biol Chem 270:25057-25063

Humphrey JS, Peters PJ, Yuan LC, Bonifacino JS (1993) Localization of TGN38 to the trans-Golgi network: involvement of a cytoplasmic tyrosine-containing sequence. J Cell Biol 120: 1123-1135

Johnson PA, Stieber A, Gonatas NK (1994) A hypothesis on the traffic of MG160, a medial Golgi sialoglycoprotein, from the trans-Golgi network to the Golgi cisternae. J Cell Sci 107:529-537

Jones BG, Thomas L, Molloy SS, Thulin CD, Fry MD, Walsh KA, Thomas G (1995) Intracellular trafficking of furin is modulated by the phosphorylation state of a casein kinase II site in its cytoplasmic tail. EMBO J 14:5869-5883

Jones SM, Crosby JR, Salamero J, Howell KE (1993) A cytosolic complex of p62 and rab6 associates with TGN38/41 and is involved in budding of exocytic vesicles from the trans-Golgi network. J Cell Biol 122:775-788

Jung E, Fucini P, Stewart M, Noegel AA, Schleicher M (1996) Linking microfilaments to intracellular membranes: the actinbinding and vesicle-associated protein comitin exhibits a mannose-specific lectin activity. EMBO J 15:1238-1246

Kleene R, Berger EG (1993) The molecular and cell biology of glycosyltransferases. Biochim Biophys Acta 1154:283-325

Kooy J, Underwood JR, Gleeson PA (1991) Identification of components of the endoplasmic reticulum and Golgi complex by murine autoreactive monoclonal antibodies. Immunology $72: 418-425$

Kornfeld R, Kornfeld S (1985) Assembly of asparagine-linked oligosaccharides. Annu Rev Biochem 54:631-664

Kornfeld S (1992) Structure and function of the mannose-6-phosphate/insulin-like growth factor receptors. Annu Rev Biochem 61:307-330

Krijnse Locker J, Griffiths G, Horzinek MC, Rottier PJ (1992) $O$ Glycosylation of the coronavirus M protein. Differential localization of sialyltransferases in $\mathrm{N}$ - and $\mathrm{O}$-linked glycosylation. J Biol Chem 267:14094-14101

Krijnse Locker J, Ericsson M, Rottier PJM, Griffiths G (1994a) Characterization of the budding compartment of mouse hepatitis virus - evidence that transport from the RER to the Golgi Complex requires only one vesicular transport step. J Cell Biol 124:55-70

Krijnse Locker J, Klumperman J, Oorschot V, Horzinek MC, Geuze HJ, Rottier PJM (1994b) The cytoplasmic tail of mouse hepatitis virus $\mathrm{M}$ protein is essential but not sufficient for its retention in the Golgi complex. J Biol Chem 45:2826328269

Krijnse Locker J, Opstelten D-JE, Ericsson M, Horzinek MC, Rottier PJM (1995) Oligomerization of a trans-Golgi/trans-Golgi network retained protein occurs in the Golgi complex and may be part of its retention. J Biol Chem 270:8815-8821

Kumar R, Yang J, Larsen RD, Stanley P (1990) Cloning and expression of $\mathrm{N}$-acetylglucosaminyltransferase I, the medial Golgi transferase that initiates complex $N$-linked carbohydrate formation. Proc Natl Acad Sci USA 87:9948-9952

Ladinsky MS, Howell KE (1992) The trans-Golgi network can be dissected structurally and functionally from the cisternae of the Golgi complex by brefeldin-A. Eur J Cell Biol 59:92105

Ladinsky MS, Kremer JR, Furcinitti PS, Mcintosh JR, Howell KE (1994) HVEM tomography of the trans-Golgi network: structural insights and identification of a lace-like vesicle coat. J Cell Biol 127:29-38

Lewis MJ, Pelham HR (1992) Ligand-induced redistribution of a human KDEL receptor from the Golgi complex to the endoplasmic reticulum. Cell 68:353-364
Linstedt AD, Hauri H (1993) Giantin, a novel conserved Golgi membrane protein containing a cytoplasmic domain of a least $250 \mathrm{kDa}$. Mol Biol Cell 4:679-693

Low SH, Tang BL, Wong SH, Hong W (1994) Golgi retardation in Madin-Darby canine kidney and Chinese hamster ovary cells of a transmembrane chimera of two surface proteins. J Biol Chem 269:1985-1994

Luján HD, Marotta A, Mowatt MR, Sciaky N, LippincottSchwartz J, Nash TE (1995) Developmental induction of Golgi structure and function in the primitive eukaryote Giardia lamblia. J Biol Chem 270:4612-4618

Lussier M, Sdicu A-M, Ketela T, Bussey H (1995) Localization and targeting of the Saccharomyces cerevisiae Kre2p/Mnt1p $\alpha 1,2$-mannosyltransferase to a medial-Golgi compartment. J Cell Biol 131:913-927

Luzio JP, Banting G (1993) Eukaryotic membrane traffic: retrieval and retention mechanisms to achieve organelle residence. Trends Biochem Sci 18:395-398

Luzio JP, Brake B, Banting G, Howell KE, Braghetta P, Stanley KK (1990) Identification, sequencing and expression of an integral membrane protein of the trans-Golgi network (TGN38). Biochem J 270:97-102

Machamer CE (1991) Golgi retention signals: do membranes hold the key? Trends Cell Biol 1:141-144

Machamer CE, Rose JK (1987) A specific transmembrane domain of a coronavirus E1 glycoprotein is required for its retention in the Golgi region. J Cell Biol 105:1205-1214

Machamer CE, Mentone SA, Rose JK, Farquhar MG (1990) The E1 glycoprotein of an avian coronavirus is targeted to the cisGolgi complex. Proc Natl Acad Sci USA 87:6944-6948

Machamer CE, Grim MG, Esquela A, Chung SW, Rolls M, Ryan K, Swift AM (1993) Retention of a cis-Golgi protein requires polar residues on one face of a predicted alpha-helix in the transmembrane domain. Mol Biol Cell 4:695-704

Marks MS, Ohno H, Kirchhausen T, Bonifacino JS (1997) Protein sorting by tyrosine-based signals: adapting to the Ys and wherefores. Trends Cell Biol 7:124-129

Masibay AS, Balaji PV, Boeggeman EE, Qasba PK (1993) Mutational analysis of the Golgi retention signal of bovine $\beta-1,4$ galactosyltransferase. J Biol Chem 268:9908-9916

Matsuoka Y, Chen S-Y, Compans RW (1994) A signal for Golgi retention in the bunyavirus G1 glycoprotein. J Biol Chem 269:22565-22573

Matsuoka Y, Chen S-Y, Holland CE, Compans RW (1996) Molecular determinants of Golgi retention in the Punta Toro virus G1 protein. Arch Biochem Biophys 336:184-189

Melin L, Persson R, Ansersson A, Bergström A, Rönnholm R, Pettersson RF (1995) The membrane glycoprotein G1 of Uukuniemi virus contains a signal for localization to the Golgi complex. Virus Res 36:49-66

Mellman I, Simons K (1992) The Golgi complex: in vitro veritas? Cell 68:829-840

Mironov AA, Weidman P, Luini A (1997) Variations on the intracellular transport theme: maturing cisternae and trafficking tubules. J Cell Biol 138:481-484

Molloy SS, Thomas L, Vanslyke JK, Stenberg PE, Thomas G (1994) Intracellular trafficking and activation of the furin proprotein convertase - localization to the TGN and recycling from the cell surface. EMBO J 13:18-33

Moreman KW, Trimble RB, Herscovics A (1994) Glycosidases of the asparagine-linked oligosaccharide processing pathway. Glycobiology 4:113-125

Morré DJ, Keenan TW (1994) Golgi apparatus buds - vesicles or coated ends of tubules? Protoplasma 179:1-4

Morré DJ, Merlin LM, Keenan TW (1969) Localisation of glycosyltransferase activities in a Golgi apparatus-rich fraction isolated from rat liver. Biochem Biophys Res Commun 37:813-819

Munro S (1991) Sequences within and adjacent to the transmembrane segment of alpha-2,6-sialyltransferase specify Golgi retention. EMBO J 10:3577-3588

Munro S (1995) An investigation of the role of transmembrane domains in Golgi protein retention. EMBO J 14:4695-4704 
Nakamura N, Rabouille C, Watson R, Nilsson T, Hui N, Slusarewicz P, Kreis TE, Warren G (1995) Characterization of a cis-Golgi matrix protein, GM130. J Cell Biol 131:17151726

Narula N, Stow JL (1995) Distinct coated vesicles labeled for p200 bud from trans-Golgi network membranes. Proc Natl Acad Sci USA 92:2874-2878

Narula N, McMorrow I, Plopper G, Doherty J, Matlin KS, Burke B, Stow JL (1992) Identification of a 200-kD, brefeldin A-sensitive protein on Golgi membranes. J Cell Biol 117:27-38

Neutra M, Leblond CP (1966a) Radioautographic comparison of the uptake of galactose- ${ }^{3} \mathrm{H}$ and glucose- ${ }^{3} \mathrm{H}$ in the Golgi region of various cell secreting glycoproteins or mucopolysaccharides. J Cell Biol 30:137-150

Neutra M, Leblond CP (1966b) Synthesis of the carbohydrate of mucus in the Golgi complex as shown by electron microscope radioautography of goblet cells from rats injected with glucose- ${ }^{3}$ H. J Cell Biol 30:119-136

Nilsson T, Lucocq JM, Mackay D, Warren G (1991) The membrane spanning domain of beta-1,4-galactosyltransferase specifies trans-Golgi localization. EMBO J 10:3567-3575

Nilsson T, Pypaert M, Hoe MH, Slusarewicz P, Berger EG, Warren G (1993a) Overlapping distribution of two glycosyltransferases in the Golgi apparatus of HeLa cells. J Cell Biol 120:5-13

Nilsson T, Slusarewicz P, Warren G (1993b) Kin recognition. A model for the retention of Golgi enzymes. FEBS Lett 330:1-4

Nilsson T, Hoe MH, Slusarewicz P, Rabouille C, Watson R, Hunte F, Watzele G, Berger EG, Warren G (1994) Kin recognition between medial Golgi enzymes in HeLa cells. EMBO J 13: $562-574$

Nilsson T, Rabouille C, Hui N, Watson R, Warren G (1996) The role of the membrane-spanning domain and stalk region of $\mathrm{N}$ acetylglucosaminyltransferase I in retention, kin recognition and structural maintenance of the Golgi apparatus in HeLa cells. J Cell Sci 109:1975-1989

Nishikawa A, Ihara Y, Hatakeyama M, Kangawa K, Taniguchi N (1992) Purification, cDNA cloning, and expression of UDP- $N$ acetylglucosamine beta-D-mannoside beta- $1,4-N$-acetylglucosaminyltransferase III from rat kidney. J Biol Chem 267: 18199-18204

Nothwehr SF, Stevens TH (1994) Sorting of membrane proteins in the yeast secretory pathway. J Biol Chem 269:10185-10188

Nothwehr SF, Roberts CJ, Stevens TH (1993) Membrane protein retention in the yeast Golgi apparatus: dipeptidyl aminopeptidase $\mathrm{A}$ is retained by a cytoplasmic signal containing aromatic residues. J Cell Biol 121:1197-1209

Nothwehr SF, Bryant NJ, Stevens TH (1996) The newly identified yeast GRD genes are required for retention of late-Golgi membrane proteins. Mol Cell Biol 16:2700-2707

Oprins A, Duden R, Kreis TE, Geuze HJ, Slot JW (1993) $\beta$-COP localizes mainly to the cis-Golgi side in exocrine pancreas. J Cell Biol 121:49-59

Orci L, Glick BS, Rothman JE (1986) A new type of coated vesicular carrier that appears not to contain clathrin: its possible role in protein transport within the Golgi stack. Cell 46: 171-184

Pearse BMF, Robinson MS (1990) Clathrin, adaptors, and sorting. Annu Rev Cell Biol 6:151-171

Petris MJ, Mercer JFB, Culvenor JG, Lockhart P, Gleeson PA, Camakaris J (1996) Ligand-regulated transport of the Menkes copper P-type ATPase efflux pump from the Golgi apparatus to the plasma membrane: a novel mechanism of regulated trafficking. EMBO J 15:6084-6095

Pettersson RF (1991) Protein localisation and virus assembly at intracellular membranes. Curr Top Microbiol Immunol 170:67106

Pfeffer SR, Rothman JE (1987) Biosynthetic protein transport and sorting by the endoplasmic reticulum and Golgi. Annu Rev Biochem 56:829-852

Pimenta PF, Saraiva EMB, Sachs DL (1991) The comparative fine structure and surface glycoconjugate expression of three life stages of Leishmania major. Exp Parasitol 72:191-204
Pimplikar SW, Simons K (1993) Regulation of apical transport in epithelial cells by a Gs class of heterotrimeric $\mathrm{G}$ protein. Nature 362:456-458

Ponnambalam S, Rabouille C, Luzio JP, Nilsson T, Warren G (1994) The TGN38 glycoprotein contains two non-overlapping signals that mediate localization to the trans-Golgi network. J Cell Biol 125:253-268

Pryer NK, Wuestehube LJ, Schekman R (1992) Vesicle-mediated protein sorting. Annu Rev Biochem 61:471-516

Rabouille C, Hui N, Hunte F, Kieckbusch R, Berger EG, Warren G, Nilsson T (1995) Mapping the distribution of Golgi enzymes involved in the construction of complex oligosaccharides. J Cell Sci 108:1617-1627

Rambourg A, Clermont Y (1990) Three-dimensional electron microscopy: structure of the Golgi apparatus. Eur J Cell Biol $51: 189-200$

Rambourg A, Clermont Y (1997) Three-dimensional structure of the Golgi apparatus in mammalian cells. In: Berger EG, Roth J (eds) The Golgi apparatus. Birkhäuser, Basel, pp 37-61

Reaves B, Banting G (1994) Overexpression of TGN38/41 leads to mislocalisation of gamma-adaptin. FEBS Lett 351:448-456

Reaves B, Wilde A, Banting G (1992) Identification, molecular characterization and immunolocalization of an isoform of the trans-Golgi network (TGN)-specific integral membrane protein TGN38. Biochem J 283:313-316

Reaves B, Horn M, Banting G (1993) TGN38/41 recycles between the cell surface and the TGN: brefeldin A affects its rate of return to the TGN. Mol Biol Cell 4:93-105

Robinson MS (1997) Coats and vesicle budding. Trends Cell Biol 7:99-103

Roth J, Berger EG (1982) Immunocytochemical localisation of galactosyltransferase in Hela cells: codistribution with thiamine pyrophosphatase in trans-Golgi cisternae. J Cell Biol 92:223-229

Roth J, Taatjes DJ, Lucocq JM, Weinstein J, Paulson JC (1985) Demonstration of an extensive trans-tubular network continuous with the Golgi apparatus stack that may function in glycosylation. Cell 43:287-295

Rothman JE (1994) Mechanism of intracellular protein transport. Nature 372:55-63

Rothman JE, Orci L (1992) Molecular dissection of the secretory pathway. Nature 355:409-415

Rothman JE, Warren G (1994) Implication of the SNARE hypothesis for intracellular membrane topology and dynamics. Curr Biol 4:220-223

Russo RN, Shaper NL, Taatjes DJ, Shaper JH (1992) Beta-1,4-galactosyltransferase: a short $\mathrm{NH}_{2}$-terminal fragment that includes the cytoplasmic and transmembrane domain is sufficient for Golgi retention. J Biol Chem 267:9241-9247

Sarkar M, Hull E, Nishikawa Y, Simpson RJ, Moritz RL, Dunn R, Schachter H (1991) Molecular cloning and expression of cDNA encoding the enzyme that controls conversion of highmannose to hybrid and complex $N$-glycans: UDP- $N$-acetylglucosamine:alpha-3-D-mannoside beta-1,2- $N$-acetylglucosaminyltransferase I. Proc Natl Acad Sci USA 88:234-238

Sato K, Nishikawa S-i, Nakano A (1995) Membrane protein retrieval from the Golgi apparatus to the endoplasmic reticulum (ER): characterization of the RER1 gene product as a component involved in ER localisation of Sec12p. Mol Biol Cell 6:1459-1477

Sato M, Sato K, Nakano A (1996) Endoplasmic reticulum localization of Sec12p is achieved by two mechanisms: Rer1p-dependent retrieval that requires the transmembrane domain and Rer1p-independent retention that involves the cytoplasmic domain. J Cell Biol 134:279-293

Schachter H (1991) Enzymes associated with glycosylation. Curr Opin Struct Biol 1:755-765

Schachter H, Jabbal I, Hudgin RL, Pinteric L, McGuire EJ, Roseman S (1970) Intracellular localisation of liver sugar nucleotide glycoprotein glycosyltransferases in a Golgi-rich fraction. J Biol Chem 245:1090-1100

Schafer W, Stroh A, Berghofer S, Seiler J, Vey M, Kruse ML, Kern HF, Klenk HD, Garten W (1995) Two independent tar- 
geting signals in the cytoplasmic domain determine trans-Golgi network localization and endosomal trafficking of the proprotein convertase furin. EMBO J 14:2424-2435

Schekman R, Orci L (1996) Coat proteins and vesicle budding. Science 271:1526-1533

Scherer PE, Lederkremer GZ, Williams S, Fogliano M, Baldini G, Lodish HF (1996) Cab45, a novel Ca2+-binding protein localized to the Golgi lumen. J Cell Biol 133:257-268

Schröder S, Schimmöller F, Singer-Krüger B, Riezman H (1995) The Golgi localization of yeast Emp47p depends on its di-lysine motif but is not affected by the ret1-1 mutation in a-COP. J Cell Biol 131:895-912

Schweizer A, Rohrer J, Hauri H-P, Kornfeld S (1994) Retention of p63 in an ER-Golgi intermediate compartment depends on the presence of all three of its domains and on its ability to form oligomers. J Cell Biol 126:25-39

Schwientek T, Lorenz C, Ernst JF (1995) Golgi localization in yeast is mediated by the membrane anchor region of rat liver sialyltransferase. J Biol Chem 270:5483-5489

Seeger M, Payne GS (1992a) A role for clathrin in the sorting of vacuolar proteins in the Golgi complex of yeast. EMBO J 11:2811-2818

Seeger M, Payne GS (1992b) Selective and immediate effects of clathrin heavy chain mutations on Golgi membrane protein retention in Saccharomyces cerevisiae. J Cell Biol 118:531-540

Shaper JH, Shaper NL (1992) Enzymes associated with glycosylation. Curr Opin Struct Biol 2:701-709

Shoreibah M, Perng G, Adler B, Weinstein J, Basu R, Cupples R, Wen D, Browne JK, Buckhaults P, Fregien N, Pierce M (1993) Isolation, characterisation, and expression of a cDNA encoding $N$-acetylglucosaminyltransferase V. J Biol Chem 268: $15381-15385$

Slusarewicz P, Nilsson T, Hui N, Watson R, Warren G (1994) Isolation of a matrix that binds medial Golgi enzymes. J Cell Biol 124:405-413

Stanley KK, Howell KE (1993) TGN38/41: a molecule on the move. Trends Cell Biol 3:252-255

Stow JL, Almeida JB de, Narula N, Holtzman EJ, Ercolani L, Ausiello DA (1991) A heterotrimeric $G$ protein, $G$ alpha i-3, on Golgi membranes regulates the secretion of a heparan sulfate proteoglycan in LLC-PK1 epithelial cells. J Cell Biol 114:1113-1124

Subramaniam VN, Peter F, Philp R, Wong SH, Hong W (1996) GS28, a 28-kilodalton Golgi SNARE that participates in ERGolgi transport. Science 272:1161-1163

Suganuma T, Muramatsu H, Muramatsu T, Ihida K, Kawano J, Murata F (1991) Subcellular localization of $N$-acetylglucosaminide beta-1,4-galactosyltransferase revealed by immunoelectron microscopy. J Histochem Cytochem 39:299-309

Swift AM, Machamer CE (1991) A Golgi retention signal in a membrane-spanning domain of coronavirus E1 protein. J Cell Biol 115:19-30

Taatjes DJ, Roth J, Weinstein J, Paulson JC (1988) Post-Golgi apparatus localization and regional expression of rat intestinal sialyltransferase detected by immunoelectron microscopy with polypeptide epitope-purified antibody. J Biol Chem 263:63026309

Takahashi S, Nakagawa T, Banno T, Watanabe T, Murakami K, Nakayama K (1995) Localization of furin to the trans-Golgi network and recycling from the cell surface involves Ser and Tyr residues within the cytoplasmic domain. J Biol Chem 270:28397-28401

Tanaka K, Fukudome H (1991) Three-dimensional organization of the Golgi complex observed by scanning electron microsopy. J Electron Microsc Tech 17:15-23
Tang BL, Wong SH, Low SH, Hong W (1992) The transmembrane domain of $\mathrm{N}$-glucosaminyltransferase I contains a Golgi retention signal. J Biol Chem 267:10122-10126

Tang BL, Wong SH, Qi XL, Low SH, Hong W (1993) Molecular cloning, characterisation, subcellular localisation and dynamics of $\mathrm{p} 23$, the mammalian KDEL receptor. $J$ Cell Biol $120: 325-338$

Tang BL, Low SH, Wong SH, Hong WJ (1995) Cell type differences in Golgi retention signals for transmembrane proteins. Eur J Cell Biol 66:365-374

Teasdale RD, D'Agostaro G, Gleeson PA (1992) The signal for Golgi retention of bovine beta 1,4-galactosyltransferase is in the transmembrane domain. J Biol Chem 267:4084-4096 [erratum J Biol Chem (1992) 267:13113]

Teasdale R, Matheson F, Gleeson PA (1994) Post-translational modifications distinguish cell surface from Golgi-retained $\beta 1,4$-galactosyltransferase molecules. Golgi localization involves active retention. Glycobiology 4:917-928

Trowbridge IS, Collawn JF, Hopkins CR (1993) Signal-dependent membrane protein trafficking in the endocytic pathway. Annu Rev Cell Biol 9:129-161

Vaisberg EA, Grissom PM, McIntosh JR (1996) Mammalian cells express three distinct dynein heavy chains that are localized to different cytoplasmic organelles. J Cell Biol 133:831-842

Voorhees P, Deignan E, Vandonselaar E, Humphrey J, Marks MS, Peters PJ, Bonifacino JS (1995) An acidic sequence within the cytoplasmic domain of furin functions as a determinant of trans-Golgi network localization and internalization from the cell surface. EMBO J 14:4961-4975

Weidman P (1995) Anterograde transport through the Golgi complex: do Golgi tubules hold the key? Trends Cell Biol 5:302-305

Weiner OH, Murphy J, Griffiths G, Schleicher M, Noegel AA (1993) The actin-binding protein comitin (p24) is a component of the Golgi apparatus. J Cell Biol 123:23-34

Weisz OA, Swift AM, Machamer CE (1993) Oligomerisation of a membrane protein correlates with its retention in the Golgi complex. J Cell Biol 122:1185-1196

Wilcox CA, Redding K, Wright R, Fuller RS (1992) Mutation of a tyrosine localisation signal in the cytoplasmic tail of yeast Kex2 protease disrupts Golgi retention and results in default transport to the vacuole. Mol Biol Cell 3:1353-1371

Wilsbach K, Payne GS (1993) Dynamic retention of TGN membrane proteins in Saccharomyces cerevisiae. Trends Cell Biol 3:426-431

Winter G, Fuchs M, McConville MJ, Stierhof YD, Overath P (1994) Surface antigens of Leishmania mexicana amastigotes: characterisation of glycoinositol phospholipids and a macrophage-derived glycosphingolipid. J Cell Sci 107:24712482

Wong S, Hong W (1993) The SXYQRL sequence in the cytoplasmic domain of TGN38 plays a major role in trans-Golgi network localisation. J Biol Chem 268:22853-22862

Wong SH, Low SH, Hong W (1992) The 17-residue transmembrane domain of beta-galactoside alpha-2,6-sialyltransferase is sufficient for Golgi retention. J Cell Biol 117:245-258

Yamaguchi N, Fukuda MN (1995) Golgi retention mechanism of $\beta$-1,4-galactosyltransferase: membrane-spanning domain-dependent homodimerization and association with $\alpha$ - and $\beta$-tubulins. J Biol Chem 270:12170-12176

Zhu Z, Hao Y, Gershon MD, Ambron RT, Gershon AA (1996) Targeting of glycoprotein I (gE) of varicella-zoster virus to the trans-Golgi network by an AYRV sequence and an acidic amino acid-rich patch in the cytosolic domain of the molecule. J Virol 70:6563-6575 